\title{
System OF Protection AND Diagnostics OF STRUCTURAL Elements of Support of High-Voltage PoWer Lines
}

\author{
Iosif Breido, Vladimir Kaverin, Valeriy Ivanov, \\ Sofiya Voytkevich, Igor Levin
}
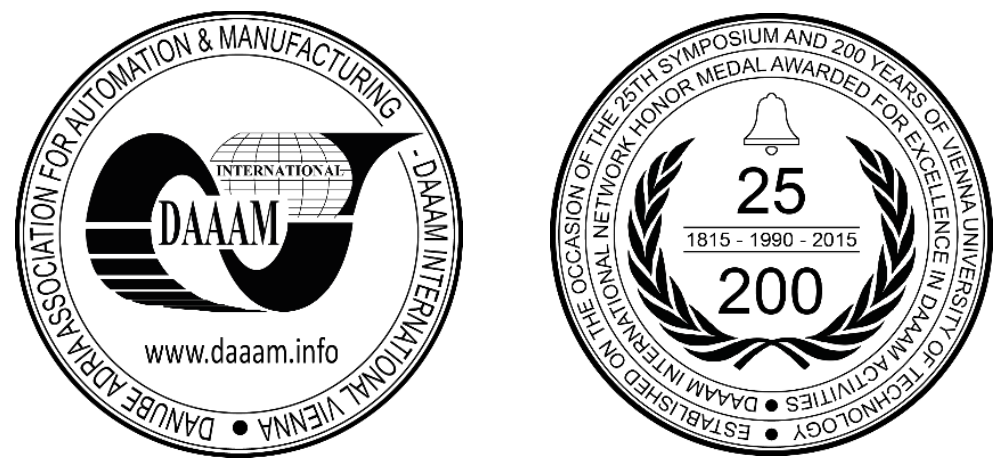

This Publication has to be referred as: Breido, I[ossif]; Kaverin, V[ladimir]; Ivanov, V[aleriy]; Voytkevich, S[ofiya] \& Levin, I[gor] (2017). System of Protection and Diagnostics of Structural Elements of Support of High-Voltage Power Lines, Proceedings of the 28th DAAAM International Symposium, pp.0322-0330, B. Katalinic (Ed.), Published by DAAAM International, ISBN 978-3-902734-11-2, ISSN 1726-9679, Vienna, Austria

DOI: $10.2507 / 28$ th.daaam.proceedings.044

\author{
Abstract \\ A distributed system of protection and diagnostics of support structural elements of high-voltage power lines (HVPL) on \\ $500 \mathrm{kV}$ voltage was developed at Karaganda State technical university: \\ - current monitoring of leakage currents of bunches of suspension insulators; \\ - detection ice-rime depositions; \\ - cathode protection of underground elements of support constructions; \\ - information transfer from the sensors placed on supports on the control office on telemetric channels; \\ - creation of the passport of each support on SCADA - system basis.
}

The system contains set of local subsystems of protection, measurement, processing and information transfer on support, communication links and a subsystem processing and information storage on the control offices. Power supply of local subsystems is provided by the directed energy of electromagnetic fields. Detection of ice-rime deposits is carried out by the indirect methods based on the current monitoring of the support response of wind and ice loads and also temperatures and air humidity. Sensors information allows to control integral values of a leakage current of industrial frequency and surface currents of the partial discharges proceeding through strings of insulators and also to define the time-point optimum for drop-out ice-rime deposits.

Radio modem and cellular communication with an automatic choice of the communication channels in the conditions of the powerful electromagnetic fields have a significant effect on an opportunity and transmission quality of information are used for transmission the telemetric information to the control office. Tests with the positive results of the experimental samples of all components of system are carried out on the operating line and in laboratories. The developed system is a basis for methods creation and technical solutions on lowering the losses of the electric power in case of its transportation on 110 and $220 \mathrm{kV}$ HVPL.

Keywords: High-voltage power lines, system of protection and diagnostics, telemetry, alternative channel. 


\section{Introduction}

In the CIS countries power transmission on long distances is carried out by air high-voltage power lines (HVPL) [1].

Any accident, on HVPL of 110-500 kV, connected with arc overlapping suspended insulators, break of current carrying wires, supports falling, leads to interruptions of power supply of the whole regions.

Reliability of work and size of active losses of the HVPL electric power extremely depends on a condition of suspended insulators. Now remote contactless ways of preventive control of insulators with use of electron-optical defectoscopes [2-7] are used. Realization of these methods requires direct visual contact with supports therefore diagnostics can be made only selectively and with a big frequency. Therefore they are inapplicable for the supports established in boggy places, in mountainous and rocky areas. Big errors arise because of a corona effect on suspended insulators and influences of solar illumination at their use.

Considerable influence on reliability of power transmission on air-lines in the conditions of Kazakhstan and Russia is rendered by extreme climatic factors, including the ice-rime depositions leading to severe accidents (to $30 \%$ of emergency HVPL shutdowns) [8-10].

There are various ways of measurement control of the ice load of the current carrying elements of overhead power transmission lines [10-13] based on the analysis of various physical effects accompanying ice depositions. However these ways weren't widely adopted because of insufficient sensitivity, big mistakes, and also high complexity and insufficient reliability of ice detection on HVPL.

Essential decrease in a resource of support is caused by processes of electrochemical corrosion of the elements of fastening located underground, and protection systems against these processes on HVPL are absent.

Lack of the existing control methods and HVPL protection is their fragmentariness, they are not compatible among themselves and cannot be applied to continuous complex monitoring of a condition of each of the HVPL supports.

At the Karaganda State technical university the distributed system of protection and diagnostics of structural elements of the HVPL supports was developed [14-20]:

- current control of currents of bunches leakage of the suspended insulators;

- identification ice-rime depositions;

- cathodic protection of underground elements of the support constructions;

- information transfer from the sensors placed on support on control office on telemetric channels;

- creation of each support passport on the basis of SCADA - system.

Distinctive feature of system is its complexity that has allowed to solve within one project problems of protection and diagnostics of construction elements of HVPL in various parameters on the basis of the integrated telemetry and uniform approaches to design.

As a result, the experimental sample of system was developed on this basis, technical and scientific novelty of which was confirmed with inventions [16, 18, 19].

High reliability of the telemetry channel is provided with use of various communication channels between the local subsystems located on the HVPL support and a subsystem of processing and storage of information at control offices with automated variant choice (radio modem and cellular communication).

\section{Description and characteristics of the protection system and diagnostics}

The protection and diagnostics system represents set of the local of protection, measurement, processing and information transfer on supports, communication channels and a subsystem of processing and storage of information at control offices.

Separated phase sensors of leakage currents of strings of suspended high-voltage insulators are placed on each support.

There is insulator aging because of influence of powerful electromagnetic fields, surface discharges, a coronaformation, influences of the environment in use. Researches of currents statistics of leak on polymeric insulators have shown that the range of their change is less than $0.5 \mathrm{~mA}$ - to more than $25 \mathrm{~mA}$ depending on a condition of the insulators surface [21]. According to size of currents of leak it is possible to estimate a resource of isolation centers indirectly.

The combined sensor of leakage currents of suspended insulators strings which feature is a control of integrated values of leakage current of industrial frequency and current of partial discharge which design considers features of fastening in the grounded part of the suspended isolation center [22]. Sensors are placed between the top plates of strings on each phase and the top grounded traverses of supports.

About a condition of high-voltage polymeric insulators we can judge by currents of leak and gradual increase in quantity of impulses of partial surface discharges for a discrete phase interval of tension to serially going one by one partial discharges. It is a characteristic of a pre-breakdown situation of insulators [23]. Thus, a control of the surface discharges frequency and volume leak current allows to estimate an operational condition of a string of high-voltage insulators. Power supply is implemented on wires in the combined current sensor, and information from his outputs is transmitted through a radio modem that increases reliability and noise stability of the system. The structural diagram of the current sensor is showed in the figure 1. 
The hybrid current sensor controls two parameters of leakage currents of suspension insulators HVPL [24]:

- an average value of the background leakage current module of the industrial frequency;

- an average value of the surface current module of the partial discharges.

The hybrid sensor consists of:

- a current sensor of the partial discharges - CSPD;

- a sensor of the background leakage current of industrial frequency - SBCIF;

- a current sensor controller - CSC;

- a radio modem - RM;

- a power supply unit - PSU.

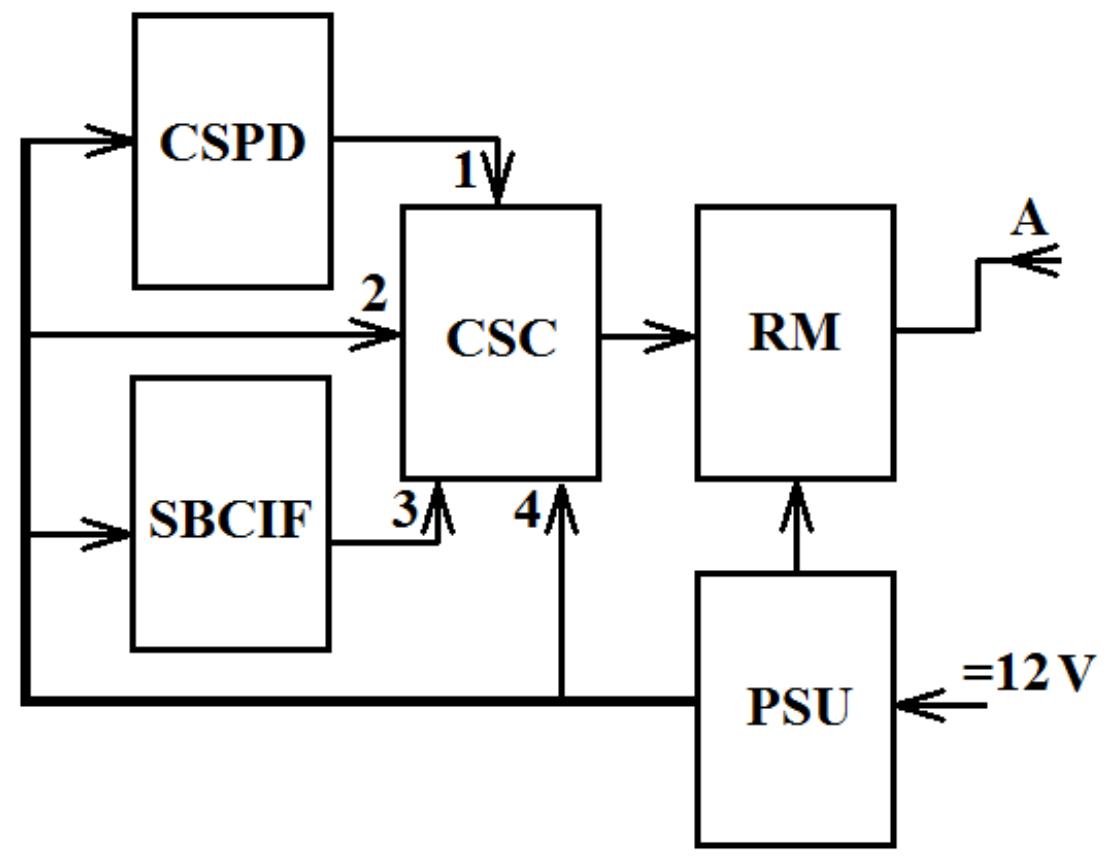

Fig. 1. The structural diagram of the sensor of leakage currents

A controller of the current sensor performs the following functions:

- constant inquiry of information analog outputs of CSPD and SBCIF, and also processing of the test signal with 1B tension, created by power supply unit and the discrete signals of synchronization in the cyclic mode;

- averaging of multiply repeated information signals from CSPD and SBCIF output;

- computation of admissible value of a zone of an output signals dispersion from CSPD and SBCIF sensors;

- synchronization of the controller current time of the control local subsystem (CLSS) and CSC in the cyclic mode.

- transfer of average signals of separated phase sensors of leak currents through a radio modem on a support in CLSS.

The following information signals are formed in memory of the sensor controller of current on the termination of the analyzed time interval:

1. test signal of $1 \mathrm{~V}$;

2. average signal of the background current size of the industrial frequency leakage;

3. average signal of current size of partial discharges;

4. value of admissible size of a zone of dispersion of an output signal of the sensor of background current of leakage of industrial frequency;

5. value of admissible amount of a zone of an output signal dispersion of the current sensor of partial discharges;

6. the current time of data recording in non-volatile memory;

7. code number with information number of a support and phase of the controlled insulator (record of a code with information about a support number and each of three phases is made right after completion of installation of three sensors of current on suspended insulators of current carrying wires of three phases in non-volatile memory of the current sensors controllers).

The physical form of an experimental sample of the sensor of leak current without the top cover is showed in the figure 2, where 1 - block of coordination of the current sensor of partial discharges, 2 - primary converter of the sensor of current of partial discharges, 3 - primary converter of the sensor of volume (background) leak current, 4 - block of coordination of the sensor of volume current, 5 - the converter of supply voltage of the combined current sensor, 6 current sensor controller, 7 - radio modem. 


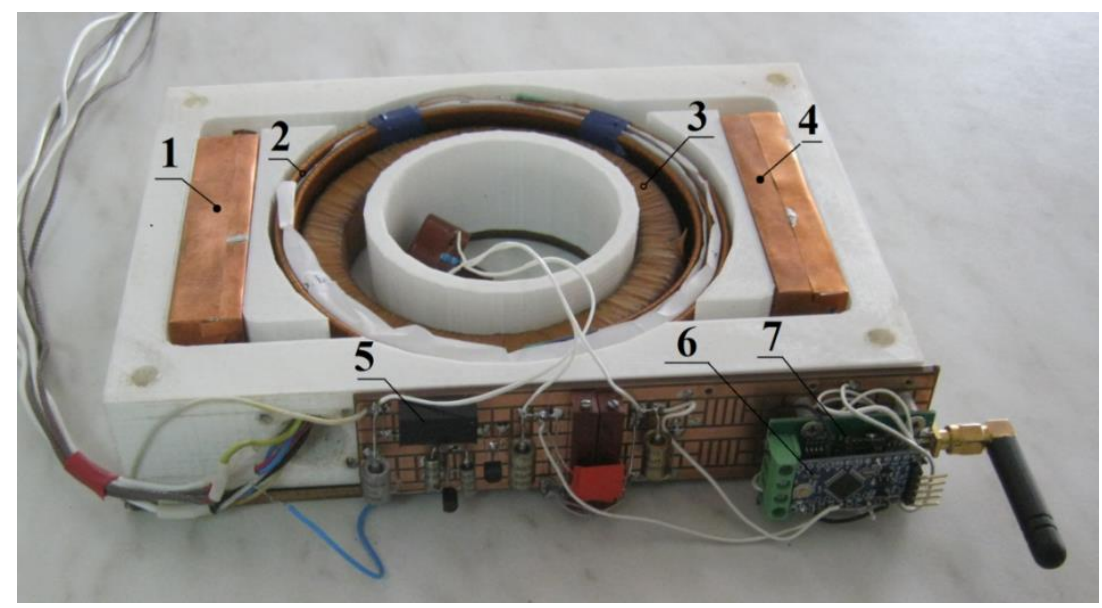

Fig. 2. An experimental sample of the combined current sensor

CSPD consists of primary converter performing functions of a galvanic outcome and current transformation of partial discharges to the electric signal coordinated on amplitude with input circuits of intensifying cascades and also the electronic block which performs functions of strengthening with the subsequent straightening and allocation of a constant component. In SBCIF functions of a galvanic outcome of primary converter with elements of fastening of the suspended insulator and also transformation of a harmonious component of the leakage current of industrial frequency proceeding via the insulator in an electric signal of constant tension are realized. Signals with CSPD and SBCIF enter the ADC current sensor controller ( 1 and 3 inputs of CSC in the figure 1 respectively). The basic tension of $1 \mathrm{~V}$ enters on the CSC second input intended for control of ADC blocks operation, the controller and a radio channel. Supply voltage with PSU enters the 4th input controller. Also with PSU the stabilized tension enters the blocks - CSPD, SBCIF and RM. Information signal from the CSC output enters RM input. The telemetric signal from the output of the controller enters a radio modem input with the subsequent information transfer to the electronic block of collecting and preprocessing of information from the sensors located on a support.

CSC is executed on the Arduino-Micro platform.

The structural diagram of the local subsystem performing functions of collection and preprocessing with the subsequent transmission of the telemetric information to the control office is showed in a figure 3 .

The local subsystem solves the following issues:

- collection of information from sensors;

- control of operability of the transfer channel of telemetric information from control and indicator sensors in the controller of local system;

- preprocessing information;

- saving the information in non-volatile memory;

- testing the information channels;

- the choice of information channel with the maximum level of a signal;

- transfer the saved information to the server of control office.

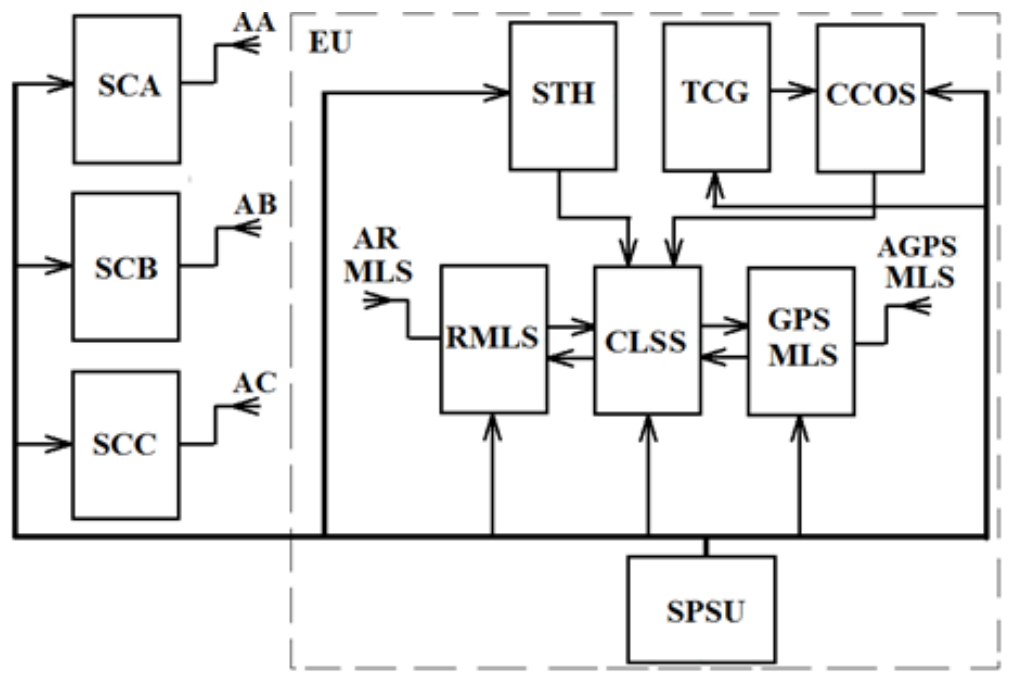

Fig. 3. Structural diagram of the local subsystem 
The local subsystem consists of three identical, hybrid sensors of current and an electronic unit. Sensors of leakage currents on phases (SCA, SCB, SCC) transfer with the given periodicity on a radio channel the current information about value of the leakage current to the electronic unit (EU). A time interval of the inquiry of current sensors changes in value of a leakage current. The maximum time of an interval of the inquiry corresponds to the minimum value of the leakage current. The interval of time is reduced with increase in a leakage current. Control of the interval time inquiry of leak current sensors is executed by the controller of local subsystem (CLSS). CLSS is executed on the Arduino-Micro platform.

The Electronic Unit (EU) includes the hybrid sensor of temperature and humidity (STH), and also a three-coordinate gyroscope (TCG), a controller of conversion of output signals of TCG is CCOS, the controller of local subsystem (CLSS), two radio modems - cellular (GPSMLS) and a radio communication (RMLS), the stabilized power supply unit (SPSSU).

CLSS has bidirectional communication through channels of transferring information with control office. The sample frequency of these sensors increases at rising of leak currents to dangerous level or at gaining the frequency and signals amplitude of current sensors of the surface discharges.

Power supply of the local subsystems is situated on supports provided from the directed energy of electromagnetic fields, entering from a lightning-protective cable $[18,19]$. For protection against tension arising during lightning strokes, inputs disconnection of PSU power supply units and SPSSU from the converter of tension of a lightning-protective cable during its action was considered.

Detection ice-rime deposits is carried out by the indirect methods based on monitoring reaction of a support to wind and ice loads.

Formation of ice and snow sticking on HVPL wires happen at high humidity higher than $85 \%$ and air temperature in limits $-(2 \div 5){ }^{\circ} \mathrm{C}$. This process can be combined with big wind loading, followed by "dancing" and sagging of wires, it is shown by significant growth in mechanical dynamic loads of support. However, snow sticking can arise also at the windless weather. At the same time the tilt angle of support along HVPL changes, if it is absence of support accelerations in the horizontal plane, that is side and longitudinal accelerations.

Therefore the current control of acceleration of a support in three planes and also temperature and humidity of air by means of signals of the combined sensor of temperature and humidity is carried out (STH: measuring instrument of humidity and temperature ИВГ-1 МК-С-M) and also three-coordinate gyroscope (TKG: three-axial accelerometer MMA7361 of Freescale company) [19].

When comparing signals of the support acceleration in three planes and a support deviation corner on HVPL axis, and also temperature signals and air humidity with the preset values, the probability of icing process origin on current carrying wires is defined [19].

Increase of noise resistance from electromagnetic fields action and a corona-development is carried out on the basis of averaging signals of sensors in controllers of sensors of current and in the local subsystem controller. It is revealed that hindrances from corona-development processes and electromagnetic fields are concentrated in the range of frequencies 6-7 MHz. Radio modems of system provide signaling at frequencies more than $2 \mathrm{GHz}$. These measures provide noise resistance of the developed system.

On each HVPL support three sensors of leak currents according to phases are placed. Sets of temperature, humidity and accelerations sensors of a support are placed on HVPL support sites where there is a frosting and the drizzle on longterm observations.

Cathodic protection is a part of system. 2 options of cathodic protection of underground elements of the HVPL support design are developed:

- The autonomous cathodic protection which does not demand power supply source, based on connection of the semiconductor diode parallel to the isolating elements in backstay cables, that is equivalent to giving of negative potential on the protected element [16].

- Cathodic protection with power supply from the energy directed in a lightning-protective cable [18].

Radio modem, cellular communication with an automatic choice of channels of transferring information in the conditions of the powerful electromagnetic fields directed in the HVPL elements when transporting the electric power is used for telemetric information transmission to the control office.

Information transfer from support on the server is executed on cellular communication in the presence of stable cellular communication. At the same time the considerable sections of HVPL-500, because of remoteness of lines from settlements, and also because of a land features, are not enveloped by cellular communication. In this regard technical capability of information transfer on a chain from a support to a support is provided to the support which has a stable cellular communication with control office.

In that case if information transfer, for any reasons does not arise, CSC continues in the cyclic mode with the given interval of time to execute inquiry of CSPD and SBCIF information channels and to make computation of average values, and also the ranges of dispersion zones of output signals for each information channel. All information taking into account the current time is saved in the CLSS non-volatile memory.

The passport of each support of a HVPL controlled section which supports archive of information on technical condition of construction elements of HVPL support, trends of leakage about the current alert conditions with localization of the place, time are created in the control office.

Predicting mathematical development models of alert conditions, and also controlled elements aging of HVPL support construction were created on the basis of the analysis of the current values of leakage, technologic forecasting of frosting HVPL current elements is provided. Diagnostics of the equipment status of local systems and sensors is performed, recommendations, on changeover of elements of HVPL support are created. 


\section{The pilot laboratory studies of system}

Due to the big organizational and technical problems of the research performance on the operating HVPL-500 line experiments have been conducted in laboratory conditions. The laboratory stand was manufactured; the structural diagram is showed in the figure 4 .

In the figure 4 the following designations are entered: 1 - information transfer device; 1.1 - a controller (Arduino Pro Mini) forming the transferring file; 1.2 - HY RS485 transferring module on the radio modem basis; 2 - the device of receiving and visualization of parameters of the accepted information; 2.1 - the module of telemetric information receiving on the basis of HY RS485 radio modem; 2.2 - a controller (Arduino Pro Mini) with the program of the analysis of reliability degree of the accepted information; 2.3 - visualization device; 3 - The simulator of the electromagnetic field created by a corona of the HVPL high-voltage wires. L1 - distance between transferring and receiving devices; L2 distance between the simulator of hindrances and the sending device.

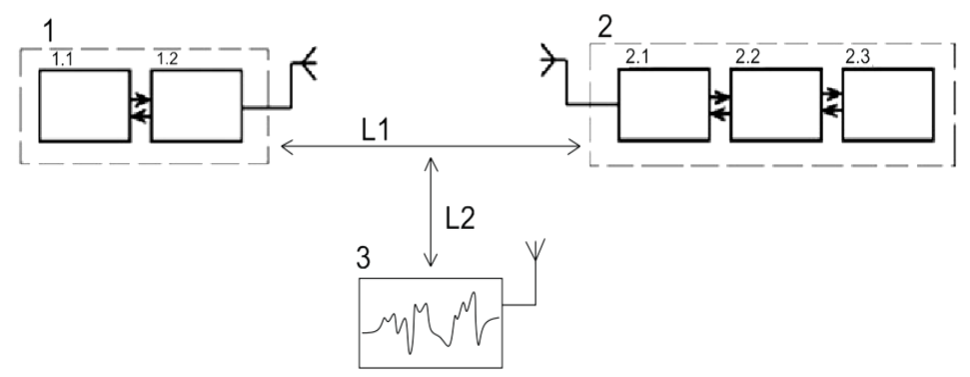

Fig. 4. Structural diagram of a subsystem of telemetric information transfer

The frequencies range of the hindrances generated by the simulator practically coincides with frequencies range of hindrances at a corona-development.

It was established that the optimum mode of data transmission was the data transmission mode with $4800 \mathrm{bit} / \mathrm{sec}$ speed. At this speed the greatest number of transfer cycles has excellent and good estimation of communication reliability. Communication reliability is characterized in number of transfer cycles as follows: bad - $20 \%$, satisfactory - $12 \%$, good $-32 \%$; excellent $-35 \%$. Data transmission deterioration is observed at increase speed of data transmission.

The average value of communication reliability at $4800 \mathrm{bit} / \mathrm{sec}$ speed for various distances between modems and radiator of hindrances is presented in the figure 5 .

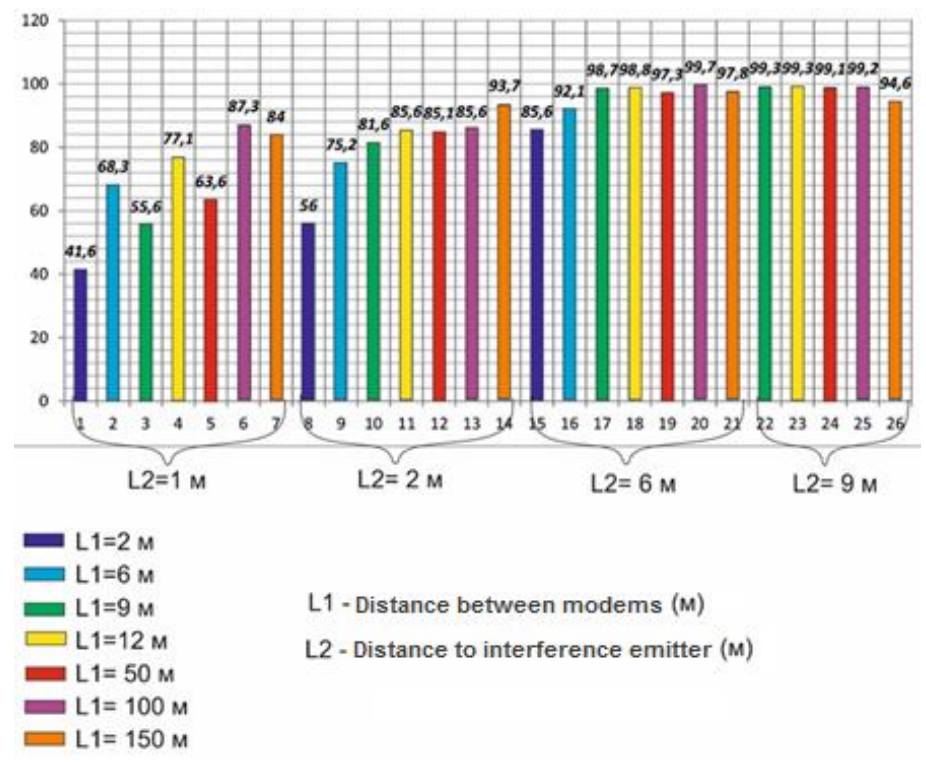

Fig. 5. Average value of communication reliability at speed $4800 \% \mathrm{bit} / \mathrm{sec}$

The number of the distorted files increase sharply at a distance less than 4 meters between the transferring module and the hindrances simulator.

Because the distance between the transferring modules, installed in leak current sensors, and current carrying wires on $500 \mathrm{kV}$ HVPL makes not less than $6 \mathrm{~m}$, it is possible to claim that the telemetric channel with high reliability will steadily transfer information. 
Laboratory experiments on a research of the channel characteristics of telemetric information transfer while using cellular communication have been also executed.

The purpose of an experiment was assessment of influence of high-frequency hindrances on GSM signal level and also on quality of data transmission.

During the research the distance between the transferring GSM modem and the generator of hindrances changed and also the structure of the environment of transfer for obtaining various levels of a GSM signal modified.

It was established that at the level of weakening of a signal $101 \mathrm{~dB}$ data were transferred without loss at distance to the hindrances simulator more than 2 meters.

During the experiment packages of data were delivered without loss, or were not transferred at all if a signal was lost. It means that algorithms of sending data from the transferring GSM modem on control office provide their full transfer without loss as in the protocol of data, there are confirming bits about correctness of information transfer. Taking into account that on real HVPL-500 distance between current carrying wires and the system of telemetric data transmission will exceed by 6 meters, influence of current carrying wires on the level of a signal of the GSM channel will be insignificant and there will be enough single duplication of data for their correct receiving on control office.

\section{Experiments on the operating HVPL-500}

Tests of cathodic protection and pilot studies of the telemetry system were conducted on the operating HVPL-500 in the territory of NURA substation.

The model of the transferring block of telemetry containing the industrial controller of modular one-plate execution and the modem of cellular communication AZIMUTH have been developed and manufactured. Information via the channel of cellular communication BEELINE and Internet operator received to laboratory on the computer of the operator;

3 signals from sensors of current cathodic protection were transmitted in real time to the telemetry channel. The step of sampling the sensors of current has been established every 5 minutes.

The software established on the computer of the operator allowed to carry out the control in real time. Numerical values of telemetric information, including time and date of sampling the sensors of current cathodic protection were transferred.

The general time of tests was 10 months.

During experimental studies continuous record of the transmitted data for the purpose of carrying out the subsequent analysis of the revolting factors influence on reliability of the transmitted data was carried out. The reliability of the accepted information was estimated in comparison of information obtained at production tests with the similar information massifs received while testing control channels of cathodic protection a condition.

Diagrams of the cathodic protection current during one month are shown in figure 6.

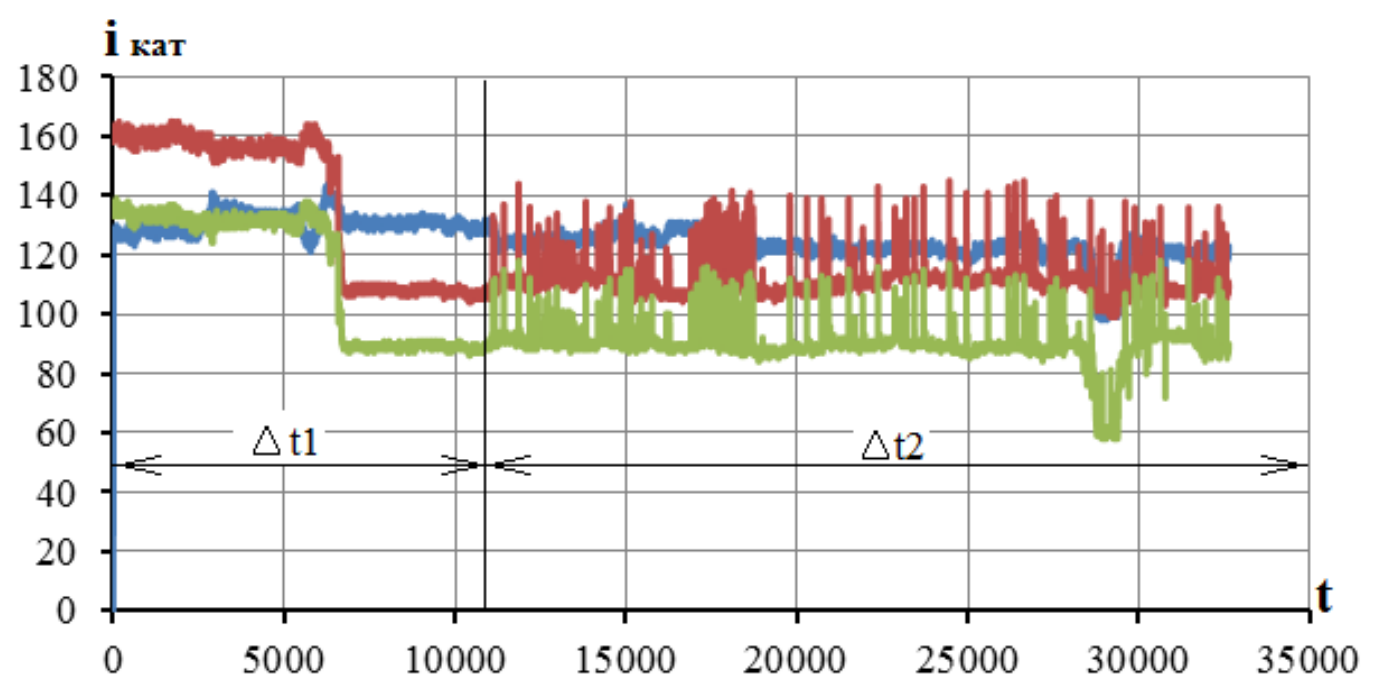

Fig. 6. The cathodic protection current during one month

Commissioning and testing of system of cathodic protection with the channel of telemetric information on the basis of cellular telephony was carried out on time interval $\Delta \mathrm{t} 1$. The system operated normally on time interval $\Delta \mathrm{t} 2$.

It is established that average loss of mass of anodes has made $11,7 \%$, the gain of mass of cathodes has made $0,7 \%$ due to the surfaces of oxide formation. After carrying out tests of cathodic protection.

Quality of the accepted telemetry is quite satisfactory. Efficiency of the cathode protection of underground elements of construction support is confirmed. The minimum values of the cathodes currents are defined, and also developed constructions of cathodes are approved. 


\section{Conclusion}

The system of protection and diagnostics of structural elements of support of high-voltage power lines (HVPL) created at Karaganda State Technical University on $500 \mathrm{kV}$ voltage, it provides monitoring of currents of strings leakage of suspended insulators, identification of the ice-rime deposits, cathodic protection of the underground elements of the design support and creation of each support passport on the basis of SCADA - system.

The carried-out tests of experimental samples on the operating line and in laboratories have confirmed operability of all system components.

Its distinctive feature is a complexity that has allowed to solve within one project problems of protection and diagnostics of elements of HVPL design in various parameters on the basis of the integrated telemetry and uniform approaches to design.

Introduction of system will allow:

- to increase reliability of strategic high-voltage HVPL due to decrease in accident rate;

- to reduce losses of the electric power at its transportation by results of remote continuous monitoring due to timely replacement of the strings of high-voltage insulators at increase in currents of leak;

- to reduce losses of the electric power at its transportation due to the reduction of spreading currents size and currents induced in metal elements of the construction support.

The developed system is a basis for creation the methods and technical solutions on decreasing losses of the electric power at its transportation on 110 and $220 \mathrm{kV}$ high-voltage HVPL.

The realized technical solutions will also be used for the complex analysis of losses on the operating high-voltage HVPL.

The components which are a part of the system have independent value and can be effectively applied to other applications. These are sensors of the leak currents, cathodic protection, the system of telemetry with use of various channels of communication.

So, sensors of the leak currents with telemetry will be used at the stands for tests of high-voltage insulators with control of the actual leak currents.

The main technical solutions created in the course of system development can be used during creation of software and hardware complexes for other applications where ensuring continuous control of the distributed electrical power systems is necessary.

\section{References}

[1] V. I. Chemodanov, N. V. Bobylyova., N. N. Utts. (2009). Development of the single national network in the existent economic conditions.//Electro. Russia, Moscow No. 5. pp. 2-7

[2] V. A. Oblozhin. (2000). Thermovision monitoring in case of the repairs organization of the electrotechnical equipment on its status. Power plants. No. 6. pp. 58-63.

[3] Methodical instructions for distant optical checking of insulation of air-lines of the electricity transmission and distributing devices of an alternating current 35 - $1150 \mathrm{kV}$. (2005). 56947007-29.240.003-2008 JSC "Federal network company of the unified power system". M. pp. 14-15.

[4] S.A. Bazhanov. (2001). Perspectives of infrared diagnostics use in power engineering//Power engineerings.. No. 8. pp. 31-32.

[5] M. N. Badretdinov, A. M. Gataullin, V. L. Matukhin, D.F. Gubayev. (2011). A method of non-contact and distant control of a bunches status of insulators of air high-voltage power lines, a patent No. 2359280 of 10.12.2011, Russia.

[6] N. M. Schmidt, I. M. Schmidt. (2001). A method of non-contact and distant control of electrodurability of bunches of insulators of air high-voltage power lines, the patent No. 2058559 of 17.09.2001, Russia.

[7] H.H. Tikhodeev. (1993). Test methods and reliability of the equipment for substations of high, super and ultrahigh tension;//News of RAS. Power engineering. - No. 3.1. pp. 42-60.

[8] E.V. Zakamsky, R. G. Minullin. (2002). The analysis of the experimental data obtained in case of diagnostics of airlines of an electricity transmission//Materials of reports of VI Postgraduate and master scientific seminar of KSEU. Kazan: KSEU, pp. 45-46.

[9] A. L. Kulikov. (2010). A method of detection of ice formation on wires and lightning-protective ropes of power lines, a patent No. 2409882 of 27.01.2010, Russia.

[10] A.F. Dyakov, I.I. Levchenko, A. S. Zasypkin, A. A. Alliluyev, E. I. Satsuk, A. I. Bytkin, F. A. Dyakov. (2005). Information systems of monitoring of ice loadings on air-lines//Power engineering specialist. No. 11. pp. 20-25.

[11] I.F. Hasanoff, M.F. Latypov, M.I. Vafin. (2001). Classification of sensors of ice on air power transmission lines//Interuniversity scientific materials "Electrotechnical Complexes and Systems" Ufa: Ufa state.avia university. pp. 202-205. 
[12] S.Voytkevich, I. Breido, V. Kaverin. (2014). Universal mathematical model of leakage currents and Currents Spread on Elements of High-Voltage Pillar. In Annals of DAAAM for 2014\& Proceedings of 25th International DAAAM Symposium. Vienna: DAAAM International, 2014. ISBN 978-3-901509-73-5. ISSN 1726-9679.

[13] I. V. Breydo, V. V. Kaverin, A.U. Nenchenko. (2016) Application of smart grid concept in the control system and condition forecasting of HVPL supports. Materials of the international scientific and practical conference "Integration of Science, Education and Production - a Basis of Implementation of the Plan of the Nation". Part 4. June 22-24.

[15] I. V. Breydo, V. V. Kaverin, V. A. Ivanov, A. V. Sichkarenko, I. V. Levin, S. V. Voytkevich. (2016). The distributed noiseproof control complex of a condition of support of high-voltage power lines. Innovative solutions of economy problems of Belarus and Kazakhstan knowledge. Collection of materials of a scientific and practical conference, Minsk. October 13. pp. 94-95.

[16] I.V. Breydo, V.V. Kaverin, A. K. Beysenov, Yu.S.Laistsev, A.V. Voytkevich, S.V. Voytkevich. (2017). Patent of RK No. 98220. "Support of overhead power transmission lines", registered on 16.05.2017.

[17] Voytkevich S., Breido I., Kaverin V. (2014). Alternative sources of supply for stand-alone automation devices on supports high-voltage lines // In Annals of DAAAM for 2014 \& Proceedings of 25th International DAAAM Symposium. - Vienna: DAAAM International.

[18] I.V. Breydo, V.V. Kaverin, S.V. Voytkevich. (2015). Innovative patent of RK No. 29977. "System of cathodic protection of elements of support of sites of high-voltage power lines", registered on 19.05.2015.

[19] I.V. Breydo, V.V. Kaverin, G.A. Em, A.V. Sichkarenko, V. A. Ivanov, S.V. Voytkevich. (2017). Application for the invention "The way of telemetry of ice loadings of high-voltage power lines and system for its implementation". Application for an invention, registered No. 2017/0424.1 from 19.05.2017.

[20] I. V. Breydo, V. V. Kaverin, A.V. Sichkarenko, S. V. Voytkevich, V. A. Ivanov. (2014). The distributed systems of protection and diagnostics of elements of high-voltage power lines. International scientific and practical conference. "Science and innovative developments - to the North". Collection of theses reports. Mirny city. pp. 89-90.

[21] Vlastos A. E., Sorqvist T. (1996). Field experience of ageing and performance of polymeric composite insulators. CIGRE.

[22] I. V. Breydo, V. V. Kaverin, V. A. Ivanov, G. A Em. (2016). Development and experimental study of the sensor of leakage current of high-voltage insulators. Works of university No. 3. Kazakhstan. pp. 105-108.

[23] A.M. Gataullin. (2015). The way of contactless remote diagnostics of a condition of high-voltage polymeric insulators. Patent of the Russian Federation No. 2566391, published on 27.10.15.

[24] V. A. Ivanov, V. V. Kaverin (2016) Diagnostics of the isolation condition of high-voltage insulators in leak current size. Works of the international scientific and practical conference "Integration of Science, Education and Production — a Basis of Implementation of the Nation Plan". Part 4. June 22-24, 2016. 